\title{
A Bipartite Butyrate-Responsive Element in the Human Calretinin (CALB2) Promoter Acts as a Repressor in Colon Carcinoma Cells But Not in Mesothelioma Cells
}

\author{
Katrin Häner, Thomas Henzi, Martine Pfefferli, Esther Künzli, \\ Valerie Salicio, and Beat Schwaller* \\ Unit of Anatomy, Department of Medicine, University of Fribourg, Fribourg, Switzerland
}

\begin{abstract}
The short-chain fatty acid butyrate plays an essential role in colonic mucosa homeostasis through the capacity to block the cell cycle, regulate differentiation and to induce apoptosis. The beneficial effect of dietary fibers on preventing colon cancer is essentially mediated through butyrate, derived from luminal fermentation of fibers by intestinal bacteria. In epithelial cells of the colon, both in normal and colon cancer cells, the expression of several genes is positively or negatively regulated by butyrate likely through modulation of histone acetylation and thereby affecting the transcriptional activity of genes. Calretinin (CALB2) is a member of the EF-hand family of $\mathrm{Ca}^{2+}-$ binding proteins and is expressed in a majority of poorly differentiated colon carcinoma and additionally in mesothelioma of the epithelioid and mixed type. Since $C A L B 2$ is one of the genes negatively regulated by butyrate in colon cancer cells and butyrate decreases calretinin protein expression levels in those cells, we investigated whether expression is regulated via putative butyrate-responsive elements (BRE) in the human CALB2 promoter. We identified two elements that act as butyrate-sensitive repressors in all colon cancer cell lines tested (CaCo-2, HT-29, Co-115/3). In contrast, in cells of mesothelial origin, MeT-5A and ZL34, the same two elements do not operate as butyrate-sensitive repressors and calretinin expression levels are insensitive to butyrate indicative of cell type-specific regulation of the CALB2 promoter. Calretinin expression in colon cancer cells is negatively regulated by butyrate via a bipartite BRE flanking the TATA box and this may be linked to butyrate's chemopreventive activity.
\end{abstract}

KEY WORDS: COLON CANCER; CALRETININ; CALCIUM-BINDING PROTEIN; EF-HAND; BUTYRATE; DIFFERENTIATION

$\mathrm{C}$ olorectal cancer is one of the main causes of cancer-related mortality in Western societies and epidemiological, clinical and experimental evidence support the hypothesis that diet is an important factor for the modulation of this disease [Reddy, 2000]. Different classes of molecules are discussed as promising chemopreventive agents and comprise calcium, vitamin D, folate [Lamprecht and Lipkin, 2003] and short chain fatty acids (SCFA) including butyrate [Siavoshian et al., 1997]. The latter is the product of the luminal fermentation of dietary fibers by intestinal bacteria and is found in millimolar concentrations in the luminal milieu in the colon. It is taken up by epithelial cells by the colonic luminalmembrane butyrate transporter, MCT1 [monocarboxylate transporter 1; Daly et al., 2005] and serves as the principal energy source for these cells [Roediger, 1982]. Previous studies have shown that highfiber diets decrease the incidence of colorectal cancer and SCFAs including butyrate are involved in the regulation of cell growth, differentiation and apoptosis. Butyrate has the capacity to modulate histone acetylation by acting as a potent inhibitor of histone deacetylases (HDACs) and thereby modifies transcriptional activity of several genes. Described effects of butyrate include the downregulation of cyclin D1 (CCND1) [Lallemand et al., 1996], the induction of the inhibitor of cyclin-dependant kinases p21 WAF1/Cip1 (CDKN1A) [Nakano et al., 1997] and the peroxisome proliferator activated receptor gamma (PPAR $\gamma$ ) [Schwab et al., 2006] finally leading to the blockage of the cell cycle and the induction of apoptosis in colon cancer cells. The mediators of this effect are still poorly characterized, but in recent years, several genes have been identified, which are regulated in a butyrate-dependent manner. These include the zinc finger transcription factor Krüppel-like factor-4 (KLF-4) [Chen et al., 2004], intrinsic trefoil factor (ITF) [Tran et al., 1998], glycoprotein hormone $\alpha$-subunit (GPH $\alpha$ ) [Haas et al., 1999], the insulin-like growth factor binding protein-3 (IGFBP-3) 
[Tsubaki et al., 2002], transient receptor potential vanilloid type 6 (TRPV6) [Fukushima et al., 2009] and the CaBP calbindin D-28k (CALB1) [Gill and Christakos, 1993].

In most cases, the modulation occurs through $\mathrm{Sp} 1$ sites or putative butyrate-responsive elements (BRE) in the promoter regions of these genes. These elements mainly act as enhancers and most often butyrate induces expression as shown for KLF-4, WAF1/Cip1, GPH $\alpha$, IGFBP-3, TRPV6, CB and PPAR $\gamma$, but may also act as repressors as shown for CCND1. We had previously shown that the addition of butyrate to the colon cancer cell line WiDr blocks cell growth, concomitant with a decrease in the expression of the $\mathrm{Ca}^{2+}$ binding protein calretinin (CR) [Schwaller and Herrmann, 1997]. CR is normally expressed in a subset of neurons in the central and peripheral nervous system [for a review, see Baimbridge et al., 1992] and additionally in other specific cell types of selected organs and tissues (e.g., testis, ovary). The precise physiological role of CR in these cells is as yet unknown, but a role of CR in regulating neuron excitability and associated cerebellar function has been demonstrated before [Bearzatto et al., 2006]. Aberrant CR expression is observed in a majority of mesotheliomas of the epithelioid and mixed type [Doglioni et al., 1996; Gotzos et al., 1996b] and in a large proportion $(>65 \%)$ of poorly differentiated (GIII) colon tumors [Gotzos et al., 1999]. Many colon cancer cell lines used as models to investigate tumorigenesis (e.g., HT-29, WiDr), express high levels of CR [Gotzos et al., 1996a]. A role for CR in tumor biogenesis was postulated based on two findings: I) Downregulation of CR by antisense methods blocks the cell cycle at G1/S and leads to increased apoptosis [Gander et al., 1996] closely resembling the effects of butyrate and II) Overexpression of CR or the alternatively splice product CR-22k [Schwaller et al., 1995] increases the resistance of the CR-negative cell line Caco-2 towards butyrateinduced growth inhibition and differentiation [Marilley et al., 2001]. Thus, we investigated whether the promoter region of the CALB2 gene contains butyrate-responsive elements (BRE) acting as transcriptional repressors and whether these putative elements are functional in different types of CR-positive cells including colon cancer cells and cells of mesothelial origin. Our results demonstrate the presence of six putative BREs in the CALB2 promoter. BRE5 and BRE6 (position -115 to -104 and -67 to -58 nucleotides before the start codon) embracing the TATA box appear to be the essential elements conferring repression of $\mathrm{CR}$ expression in colon cancer cells. These elements act as transcriptional repressors selectively in colon cancer cells, but not in cells of mesothelial origin.

\section{MATERIALS AND METHODS}

\section{CELL LINES, CELL CULTURING, TRANSFECTION EXPERIMENTS, AND TREATMENT WITH SODIUM BUTYRATE}

The colon carcinoma cell lines Caco-2 (HTB-37), HT-29 (HTB-38) and WiDr (CCL-218) as well as the SV40-immortalized mesothelial cell line MeT-5A (CRL-9444) were obtained from American Type Culture Collection (ATCC, Rockville, MD). The colon carcinoma cell line Co-115/3 [Carrel et al., 1976] and the mesothelioma cell line ZL34 [Schmitter et al., 1992] have been used in previous studies and were kept frozen as a stock at $-145^{\circ} \mathrm{C}$ [Gotzos et al., 1996a; Saydan et al., 2001]. All cell lines were cultivated as described before at $37^{\circ} \mathrm{C}$, in an atmosphere containing $5 \% \mathrm{CO}_{2}, 95 \%$ air and with a relative humidity of 95\%. The following media were used: for WiDr cells, EF medium, a mixture (1:1) of EMED (an enriched Dulbecco's modified Eagle's medium) and FMED (modified Ham's F-12 nutrient mixture); for Co-115/3 and for HT-29: McCoy's medium; for Caco-2: MEM with Earle's BSS; for MeT-5A: D-MEM/ F-12 (1:1) + GlutaMax (Gibco, Invitrogen AG, Basel, Switzerland) and for ZL34 cells: RPMI 1640 medium (Gibco) with $2 \mathrm{mM}$ L-glutamine. All media were supplemented with 10\% fetal calf serum, $10^{4} \mathrm{U} / \mathrm{L}$ penicillin and $10^{4} \mu \mathrm{g} / \mathrm{L}$ streptomycin. The cells were regularly passaged by trypsinization $\left(0.25 \%\right.$ trypsin in $\mathrm{Ca}^{2+}$ and $\mathrm{Mg}^{2+}$ free phosphate-buffered saline, CMF-PBS, pH 7.2). Trypsinisation of all lines was performed when confluency reached approximately $70-80 \%$. The different cell lines were treated with various sodium butyrate concentrations (NaBt; Sigma, Buchs, Switzerland; 0.1-10 mM; see Results Section) for various periods by adding aliquots of a $1 \mathrm{M}$ stock solution (dissolved in CMF-PBS) to the culture media.

\section{ISOLATION OF GENOMIC DNA}

For the isolation of genomic DNA or protein extracts, cells were trypsinized, centrifuged (1,000 $\mathrm{g}$, RT, $3 \mathrm{~min})$, and pelleted cells were washed twice with CMF-PBS. Genomic DNA was isolated from cell pellets or from a small piece of tissue from a colon biopsy as described before [Vonlanthen et al., 2007] using standard methods. DNA $(0.5 \mu \mathrm{g})$ was used to amplify different parts of the promoter regions of the human CR gene (for details and primer sequences, see Fig. 1). Most PCR primers contain restriction sites allowing the directional cloning of the various fragments in the plasmid pGL3Promotor (pGL3-P); Promega; \# U47298; Wallisellen, Switzerland. The amplified PCR fragments cloned in the reporter plasmid were verified by restriction analysis and by sequencing of the insert (Microsynth AG, Balgach, Switzerland). For transfection experiments, Midi- or Maxiprep DNA (ca. 300-500 $\mu \mathrm{g}$ ) was isolated using the Wizard Plus kit (Promega, Wallisellen, Switzerland).

\section{CONSTRUCTION OF DELETION AND MUTATION VARIANTS OF THE HUMAN CR PROMOTER}

A series of promoter mutants containing up to six putative butyrateresponsive elements (BREs) were constructed using standard techniques such as amplifying PCR fragments from genomic DNA and cloning of restriction enzyme fragments in the reporter plasmid pGL3-P (Promega; \# U47298; Wallisellen, Switzerland). This plasmid contains a multi-cloning site (MCS), followed by a SV40 promoter and the luciferase cassette (luc+) is followed by an SV40 late poly (A) signal. Details for the construction of the various reporter plasmids are listed below and are schematically shown in Figure 1 and Table I. As template for PCR, genomic DNA isolated from the colon cancer cell line WiDr was used. Using the plasmid containing all six elements (BRE1-6/pGL3-P), additional constructs were produced by digesting the BRE1-6/pGL3-P with SacI and either SmaI, PmlI, or ApaI (Fig. 1B), the SacI site was filled by Klenow fragment generating blunt ends and re-ligating the vector by adding T4 Ligase. This yielded the plasmids BRE2-6/ pGL3-P, BRE4-6/pGL3-P, and BRE5-6/pGL3-P, respectively. All plasmids were analyzed by restriction enzyme digestions and DNA 


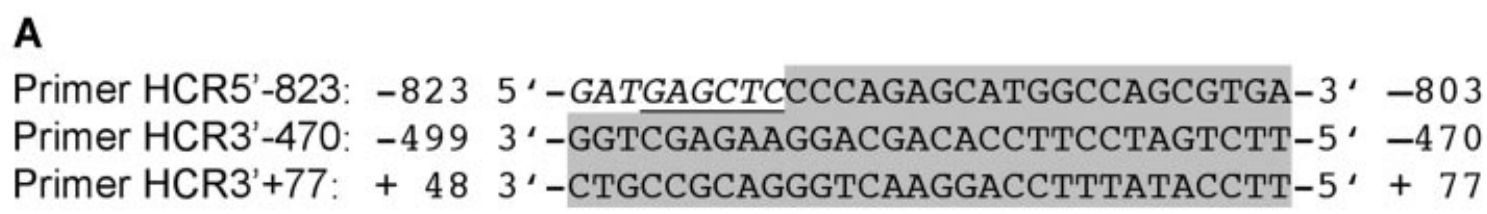

B

HCR5'-823 BRE1

tctaaaagccccccagagcatggccagcgtcaggcaggtaccagggtgaagggaggctccga ggggacggatatacgaagacccaaacagacagtggaagccccccacccccaccccacaccac SmaI BRE2

ttccatcggaatcctcccggggcactgetgattccagctgctccccactaaagccttgagaa BRE3 PmlI

ctcttggctgctctgcaagactgagccccatgaaggagc cacgtgcggegtggaaagagtgc tgagttcaaattgtagccctgccactaatttgctgggccagtcacttaatcatctgaagtca HCR3'-470

caagtacctcatcagaaaagtggtcccagctcttcctgctgtggaaggatcagaagagagag gcacgacagagacctagtgaactccgaagcccgagtgctaaatatttgtcaagtttgtgtta BRE4

gtattactattagtgttgttactgctgttattattattgctactgccagcaataataagtgg tggatgtactcaagacggtcgggagggaaggcaagggcagcctctccctcattttcaccgaa ApaI

aatcctccgggtgtccetggecccgegccgaggggtctcagcgcagaggtaagggccctcta ggagtccgggecgagcetctcgegecgecgeccccgecgegccgegccccggtcggattccc BRE5

tgagcgcgcgcgeccecttctggcggccgggcgcaggc gcaggctccagagcgTATATAAgg BRE6

gcagcgtggcgcacaaccccagc gcgagtgccagagcccagccggcgcggagcgggagcggt gcaggctgaggtctccgagcggctcgcCATGgctggcccgcagcagcagcccccttacctgc HCR3' +77

acctggccgagctgacggcgtcccagttcctggaaatatggaagcactttgacgcagacggt cagtaaagctcccaacttctgtgcccattggcacccagggacctgcggtgaagggggcaggg ggcggcgctgaatgcgg

C $\begin{array}{lc}\text { BRE5mut } & \text { BRE6mut } \\ \text { GG GATGCATGTGTTAGCG TATATAAGGGCAGCGTGGCGCACAACCCCAGATATCTGGAGTCAGCCC } \\ \text { GGCGCAGGCTCCAGAGCG } \\ \text { BRE5 }\end{array}$

Fig. 1. A: Primer sequences used to amplify PCR fragments containing a various number of putative BREs. Sequences not part of the CALB2 promoter region are in italics and the restriction site $S a c l$ is underlined. Primer sequences of the $(+)$ strand or the $(-)$ strand are also highlighted in the CALB2 promoter sequence (B; gray boxes). B: The CALB2 promoter region containing the six putative BREs (boxed) is shown from pos. -823 to pos. +77 (ATG $=+1$ ). The boxed nucleotides conferring to the consensus sequence GCnGGnTCCA are marked in bold. The restrictions sites used for the deletion mutants are in italics and underlined. The TATA-box region and the start codon in exon 1 are capitalized and marked bold. C: The sequences of the mutated elements BRE5mut and BRE6mut (boxed) flanking the TATA box (bold, italics) are shown. Underneath depicted are the original promoter sequences containing the BREs 5 and 6 (underlined; nucleotides conferring to the consensus sequence are marked in bold).

sequencing and were found to contain the identical sequences of the CALB2 promoter as in the PubMed database. In the plasmid BRE5-6/ pGL3-P, the putative BREs 5 and 6 were individually mutated yielding the plasmids BRE5mut-6/pGL3-P and BRE5-6mut/pGL3-P (Fig. 1C). For this $5^{\prime}$ and $3^{\prime}$ PCR primers (length $40 \mathrm{bp}$ ) containing the mutation in their $3^{\prime}$ and $5^{\prime}$ end, respectively were used together with primers in the $5^{\prime}$ and $3^{\prime}$ flanking region of the vector to produce the 2 PCR fragments with the mutated BREs at their $5^{\prime}$ or $3^{\prime}$ end. The purified PCR fragments (by agarose gel electrophoresis) were mixed at a 1:1 stochiometry and used as PCR template using 
TABLE I. Primers and Plasmids Used for the Construction of the Different Plasmids Containing Parts of the Human Calretinin Promoter

\begin{tabular}{|c|c|c|c|c|c|c|}
\hline Forward primer & Restr. site & Reverse primer & Sites in vector ${ }^{\mathrm{a}}$ & Size (bp), BREs & Plasmid name & CALB2 promoter $(\mathrm{ATG}=+1)$ \\
\hline $\begin{array}{l}\text { HCR5'-823 } \\
\text { HCR5'-823 }\end{array}$ & $\begin{array}{l}\text { SacI } \\
\text { SacI }\end{array}$ & $\begin{array}{l}\text { HCR3 }^{\prime}+77 \\
\text { HCR3 }^{\prime}-470\end{array}$ & $\begin{array}{l}\text { SacI, SmaI } \\
\text { SacI, BqlII }\end{array}$ & $\begin{array}{l}900,1-6 \\
354,1-3\end{array}$ & $\begin{array}{l}\text { pGL3-P/BRE1-6 } \\
\text { pGL3-P/BRE1-3 }\end{array}$ & $\begin{array}{l}-823 \text { to }+77 \\
-823 \text { to }-470\end{array}$ \\
\hline
\end{tabular}

\begin{tabular}{lccccc} 
Parental plasmid & Fragment del. $(\mathrm{bp})$ & Sites in vector & Size $(\mathrm{bp})$, BREs & Plasmid name & CALB2 promoter (ATG $=+1)$ \\
\hline pGL3-P/BRE1-6 & 131 & SacI, SmaI & $769,2-6$ & pGL3-P/BRE2-6 & -692 to +77 \\
pGL3-P/BRE1-6 & 217 & SacI, PmII & $683,4-6$ & pGL3-P/BRE4-6 & -606 to +77 \\
pGL3-P/BRE1-6 & 603 & SacI, ApaI & $297,5-6$ & pGL3-P/BRE5-6 & -220 to +77 \\
\hline
\end{tabular}

${ }^{a}$ Sites used in pGL3-P/BRE1-6 to produce deletion mutants BRE2-6, 4-6, and 5-6.

the outer $5^{\prime}$ and $3^{\prime}$ primers. The generated fragment was digested with NotI and XhoI and inserted into the same sites in pGL3-P. The correctness of the inserts in the new plasmids was verified by DNA sequencing.

\section{TRANSFECTION OF CELLS WITH pGL3-P REPORTER PLASMIDS AND CONTROL PLASMIDS: LUCIFERASE ASSAY \\ AND $\beta$-GALACTOSIDASE ASSAY}

The three colon cancer cell lines Caco-2, HT-29, and Co-115/3 and the 2 cell lines of mesothelial origin (MeT-5A and ZL34) were transfected with Lipofectamin 2000 (Invitrogen, Lubioscience, Lucerne, Switzerland) following the supplier's recommendations. We used 6-well plates $\left(10 \mathrm{~cm}^{2} /\right.$ well) and cells were seeded at a density of $10^{4}$ cells $/ \mathrm{cm}^{2}$. Transfection with the various plasmids $(2 \mu \mathrm{g})$ and the control plasmid pSV- $\beta$-galactosidase ( $2 \mu \mathrm{g}$; Promega; \#E1081) that contains the SV40 promoter and enhancer elements and the lacZ-cDNA coding for $\beta$-galactosidase were carried out at a confluency of 50-70\%. The next day the medium was supplemented with sodium butyrate (final concentration: 0.1-5 $\mathrm{mM} \mathrm{NaBt}$ for the cell lines Caco-2, HT-29 and Co-115/3, respectively) for $48 \mathrm{~h}$. The cells were then harvested by scraping from the 6-well plates, cells were washed twice with CMF-PBS and soluble proteins were extracted as described before [Marilley et al., 2001]. The protein concentration in the extracts was determined using the RC $D_{C}$ Protein Assay kit (Bio-Rad Laboratories AG, Reinach, Switzerland). From these, $10 \mu \mathrm{l}$ containing $2-10 \mu \mathrm{g}$ protein were used for the luciferase assay using the luciferase substrate from Promega and values are expressed per microgram of protein; all samples were measured in triplicates using a Luminometer TD-20/20 (Turner Biosystems, Sunnyvale, CA) with an integration time of $10 \mathrm{~s}$. For the normalization of the luciferase assay data, cells were cotransfected with the control plasmid pSV- $\beta$-galactosidase (Promega; \#E1081). Through the activity of $\beta$-galactosidase, the substrate 4-methylumbelliferyl- $\beta$-D-galactopyranoside (MUG, Sigma) is cleaved and the product methylumbelliferone is monitored at $460 \mathrm{~nm}$ when excited at $360 \mathrm{~nm}$. For each sample the ratio luminescence/ $\beta$-Gal activity was calculated. From sample pairs (e.g., the same cell type $\pm \mathrm{NaBt}$ ) the fold induction induced by butyrate was calculated and the value for the control reporter plasmid without insert (pGL3-P) was set to 100\% for each experiment. This was to standardize the data and to eliminate inter-experimental variations due to cell confluency and other cell culture related variability.

\section{SDS-PAGE AND WESTERN BLOTS}

For the Western blots, proteins were separated by SDS-PAGE on $12 \%$ polyacrylamide gels, transferred to membranes using a semi-dry protocol as described before [Racay et al., 2006]. The antibody CR7696 [Schwaller et al., 1993] was used to detect CR in a semi-quantitative way using the ECL system as described before [Racay et al., 2006].

\section{GROWTH CURVES DETERMINED BY MTT ASSAY AND FLUORIMETRIC DNA ASSAY}

Cell proliferation was determined by two methods: the MTT (3-(4,5dimethylthiazol-2-yl)-2,5-diphenyltetrazolium bromide) assay (Thiazolyl blue tetrazolium bromide; \#M5655, Sigma, Buchs, Switzerland) as described before [Schwaller and Herrmann, 1997] and the Fluorimetric DNA Assay [Rao and Otto, 1992]. In the former, the accumulation of dark blue formazan crystals inside living cells after their exposure to MTT is measured photometrically by the addition of dimethylsulfoxide (DMSO, $100 \mu \mathrm{l} /$ well) that destroys the cell membrane and solubilizes the formazan crystals. The formazan concentration is finally quantified using an ELISA-plate spectrophotometer by measuring the absorbance at $540 \mathrm{~nm}$ (Dynatec MRX, Dynatec Produkte AG, Switzerland). For each cell type, a linear relationship between cell number and optical density is established, thus allowing an accurate quantification of changes in the rate of cell proliferation. In the second assay, the quantity of DNA per sample well is determined that is directly proportional to the number of cells. Cells are seeded in 96-well plates in the presence of various concentrations of butyrate and incubated for periods of 1-4 days. After removing the medium and washing the cells with PBS, cells are lysed in $10 \mu \mathrm{l} \mathrm{SSC}$ buffer ( $15 \mathrm{mM}$ sodium citrate, $150 \mathrm{mM} \mathrm{NaCl}, \mathrm{pH}$ 7.0 containing $0.2 \%(\mathrm{w} / \mathrm{v}) \mathrm{SDS}$ ) for $10 \mathrm{~min}$ at RT. SSC buffer without SDS $(90 \mu \mathrm{l})$ is added and samples are incubated on a rotating shaker (200 rpm) for $1 \mathrm{~h}$ at $37^{\circ} \mathrm{C}$. From the Hoechst 33258 (Sigma; 861405) working solution ( $1 \mu \mathrm{g} / \mathrm{ml}$ in SSC buffer), $100 \mu \mathrm{l}$ are added to each sample, the mixture is incubated in the dark for $15 \mathrm{~min}$ on the shaker and then measured on a Promega GloMax Multi Detection System (Ex./Em.: $350 \mathrm{~nm} / 460 \mathrm{~nm}$ ).

\section{CELL DEATH ASSAYS}

The number of dead cells was determined by the CytoTox-Glo ${ }^{\mathrm{TM}}$ Cytotoxicity Assay (Promega) according to the supplier's recommendations. Briefly, the assay measures a distinct protease activity released by dead cells that cleaves a luminogenic peptide AAF$\mathrm{Glo}^{\mathrm{TM}}$ substrate. MeT-5A (4500 cells/well) and HT-29 (8,000 cells/ 
well) cells were cultured in 96-well plates for $24 \mathrm{~h}$. Various concentrations of butyrate $(0,2.5,5$, and $7.5 \mathrm{mM})$ were added for $36 \mathrm{~h}$ and the amount of dead cells determined on a Microplate Luminometer LB96V (Berthold Technologies, Regensdorf, Switzerland). For the detection of apoptotic cells, the Caspase-Glo ${ }^{\circledR}$ 3/7 Assay (Promega) was used. In this luminescent assay, the activity of the caspases 3/7 is determined. The cleavage of a luminogenic substrate containing the DEVD sequence by caspases 3/7 leads to the production of aminoluciferin that is quantified on a Bioluminescence reader (Promega GloMax Multi Detection System). Other details (cell numbers, incubation times) are as for the Cytotoxicity Assay, except that apoptosis was assayed $24 \mathrm{~h}$ after addition of butyrate.

\section{RESULTS}

\section{EFFECT OF BUTYRATE ON CELL PROLIFERATION AND CALRETININ EXPRESSION IN THE COLON CARCINOMA CELL LINES Co-115/3, HT-29, AND Caco-2}

In line with previous findings that addition of butyrate inhibits the proliferation of the colon cancer cells WiDr [Nakano et al., 1997; Schwaller and Herrmann, 1997], HT-29 [Iacomino et al., 2001], and Caco-2 [Marilley et al., 2001], cell proliferation was also diminished in Co-115/3 cells in a butyrate concentration dependant way (Fig. 2A). Results were qualitatively the same, whether the MTT assay, reporting the combined effects of proliferation (cell number) and metabolic activity of cells or the DNA assay (directly proportional to the cell number) was used (Fig. 2B). Evidently, effects of butyrate were less pronounced using the DNA assay, since in addition to the reduced number of cells, the MTT assay also reveals the reduced metabolic activity of butyrate-treated cells that mostly accumulate in $G_{0} / G_{1}$ of the cell cycle phase [Mariadason

Fig. 2. Effect of butyrate on cell proliferation and correlation with $\mathrm{CR}$ expression. A: Representative growth curves of $\mathrm{Co}-115 / 3$ cells in the presence of butyrate (1-5 mM) treated for 6 days. Cell cultures treated with up to $1 \mathrm{mM}$ butyrate reached near-confluence at 3 days and were thus not maintained for 6 days. A concentration-dependent decrease in the MTT signal was observed, but even at $5 \mathrm{mM}$, proliferation was not completely blocked. B: Growth curves of butyrate-treated Co-115/3 cells determined by DNA assay (1-4 mM; for up to 4 days); symbols and line types for the different butyrate concentrations are the same as in (A). Like in (A) the fluorescence signal, proportional to the cell number (in arbitrary units; A.U.), decreased in a butyrate concentrationdependent manner. Note that the decrease in MTT signal was more pronounced than in the DNA assay, since the MTT assay additionally takes into account the decreased metabolic activity of butyrate-treated cells. C: DNA assay with butyrate-treated HT-29 cells. The symbols and line types for the different butyrate concentrations are identical as in (A). The growth-inhibiting effect of butyrate was stronger in HT-29 than in Co-115/3 cells. D: Growth curves for Caco-2 cells determined by MTT assay; at concentrations $>0.75 \mathrm{mM}$ butyrate, proliferation was almost completely blocked. The effect of $2 \mathrm{mM}$ butyrate on HT-29 proliferation is shown in the inset (open circles). Note that the effect is again more pronounced in the MTT assay as compared with the DNA assay; compare to curve ( $2 \mathrm{mM}$; triangles, dashed line) in (C). E: CR expression levels in Co-115/3, Caco-2 and HT-29 cells determined by Western blot analysis. A similar amount $(1 \mu \mathrm{g})$ of soluble protein was loaded; the amount of CR is at least twofold higher in Co-115/3 than in HT-29 cells. A weak specific CR signal for Caco-2 cells is only seen when at least $50-100 \mu$ g protein is loaded (not shown). et al., 2000]. In Co-115/3 cells, even at the highest dose tested ( 5 and $4 \mathrm{mM}$ ), proliferation was not completely blocked (Fig. 2A,B, respectively). At the same butyrate concentrations (1-4 mM), inhibition of proliferation evidenced with the DNA assay was clearly stronger in HT-29 cells compared to Co-115/3 cells (Fig. 2C); and already $1 \mathrm{mM}$ was sufficient to almost completely block proliferation of Caco-2 cells (Fig. 2D). Interestingly, this inversely

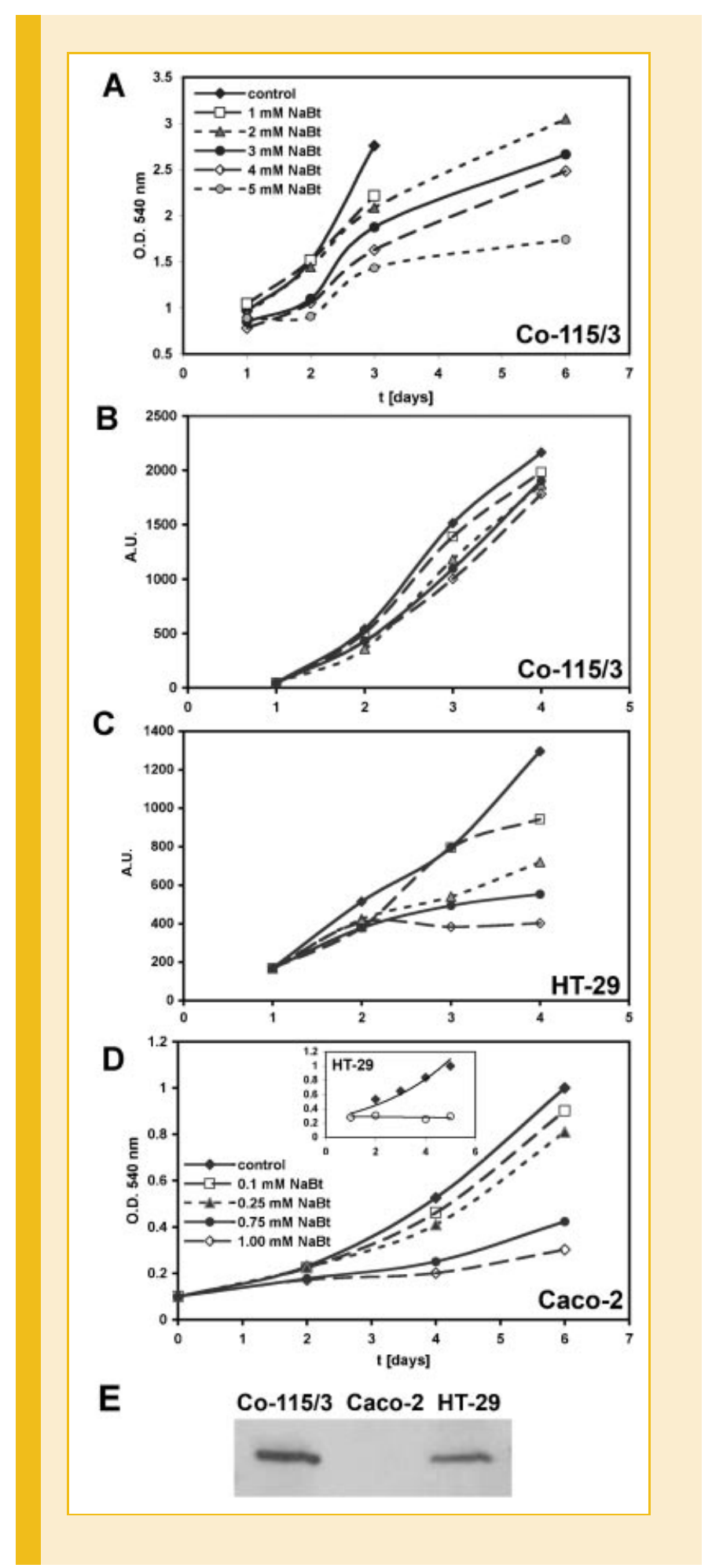




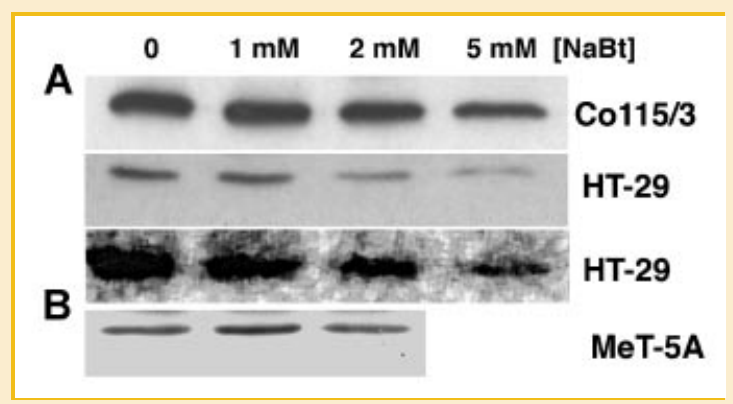

Fig. 3. Western blot analysis of $C R$ in butyrate-treated cells. $A: C R$ downregulation by butyrate in Co-115/3 and HT-29 cells. A butyrate concentrationdependent decrease in CR levels 6 days after treatment was evident in both cell lines; down-regulation was stronger in HT-29 cells. For HT-29 cells, two blots are shown: the upper one was developed with ECL using specific ECL-films, the lower one was acquired using a Phosphoimager system resulting in a more "pixeled" image. Quantification of bands yielded similar results. B: CR detection in cell extracts from the mesothelial cell line MeT-5A. From left to right: control (untreated), treatment with 1 or $2 \mathrm{mM} \mathrm{NaBt}$. No significant differences were evident after butyrate treatment.

correlates with the expression levels of CR: basal expression levels were highest in Co-115/3 cells, followed by HT-29 cells and CR levels in Caco-2 cells were extremely low, in general below the detection limit of Western blot analysis [Fig. 2E and Gotzos et al., 1996a]. In the two cell lines with detectable CR expression levels, the addition of butyrate clearly downregulated CR expression. A semiquantitative analysis of Western blot membranes indicated an approximately $80 \%$ downregulation of CR in HT-29 cells with $>2 \mathrm{mM}$ butyrate after 6 days, while downregulation in Co-115/3 was less pronounced, approximately 50\% (Fig. 3A). The results indicate that CR expression is negatively regulated by butyrate in colon cancer cells and thus we searched for elements in the promoter region of CALB2 that might confer the repressive action of butyrate.

\section{THE PROMOTER REGION OF THE HUMAN AND RODENT CALB2 GENES CONTAINS SIX PUTATIVE BUTYRATE-RESPONSIVE ELEMENTS}

Since treatment of colon carcinoma cells with butyrate leads to a down-regulation of CR [Schwaller and Herrmann, 1997; Marilley et al., 2001] we tested the hypothesis that the CALB2 gene could be directly regulated in a butyrate-dependant manner. For the closely related $\mathrm{Ca}^{2+}$-binding protein calbindin D-28k (human gene symbol $C A L B 1$ ), a butyrate-responsive element was identified in the $5^{\prime}$ flanking region of the mouse CALB1 gene between -180 and -150 that binds specifically to nuclear factors from butyrate-treated Ros 17/2.8 cells [Gill and Christakos, 1993]. In these cells, the butyrate-responsive element acts as a genetic element acted upon by enhancer binding proteins and the authors proposed this mechanism to lead to the enhanced expression of calbindin D-28k by butyrate. Similarly, the transcription of the mRNA of the glycoprotein hormone $\alpha$-subunit gene $(\mathrm{GPH} \alpha)$ is upregulated by butyrate and involves a BRE acting as an enhancer [Haas et al., 1999]. Analysis of previously described BREs for $C A L B 1, \mathrm{GPH}-\alpha$, the intestinal trefoil factor (ITF) [Tran et al., 1998], the IGF-binding protein-3 (IGFBP-3; [Tsubaki et al., 2002]) and transient receptor potential vanilloid type
6 (TRPV6) resulted in a consensus sequence of $10 \mathrm{bp}$ with highly conserved nucleotides at positions 1, 2, 4, 5, 8-10 (Fig. 4A,B), the first half often overlapping with putative Sp1 sites. A search in PubMed resulted in the identification of additional promoter regions of genes reported to be affected by butyrate (Fig. 4A). In the CALB2 promoter region between -823 and $+77(\underline{A T G}=1)$ we found 6 DNA regions named BRE1-6 matching the consensus sequence to various degrees (Fig. 4C). Further comparison with the CALB2 promoter regions of mouse and rat revealed three elements $(2,5$, and 6$)$ to be highly conserved between the three species (Fig. 4C). In addition, the nucleotide preceding the putative BREs (position 0) was highly conserved between human, rat and mouse CALB2. Nonetheless, this nucleotide was not well conserved between putative BREs 1-6 and also previously reported BREs (Fig. 4A) indicating that the nucleotide in this position is probably not an essential element (nucleotide) of the BRE.

\section{BRE5 AND BRE6 ACT AS REPRESSOR ELEMENTS IN COLON CANCER CELLS}

Since we hypothesized that the putative BREs in the CALB2 gene might act as repressors, the plasmid pGL3-P containing a SV40 minimal promoter was selected. A series of plasmids were constructed containing various numbers of the six putative BREs and the functionality of the six putative BRE elements in the CALB2 promoter were tested in the cell lines Caco-2, HT-29, and Co-115/3. The most detailed analysis were carried out in Caco- 2 cells, where transfection efficiency is superior (40-60\%) compared to the other two cell lines (typically <1\%). In Caco-2 cells, a $12.7 \pm 0.5$-fold (mean \pm SEM) increase in luciferase activity was seen with the control plasmid pGL3-P, while transfection with the plasmid pGL3BRE1-6 containing all six elements led to an approximately $40 \%$ decrease $(8.9 \pm 1.8$-fold induction; Dunnett's test $P<0.05)$ in luciferase activity when compared to pGL3-P alone (Fig. 5A,B). Similar results were found with plasmids containing BREs 2-6, 4-6, and 5-6 (for all groups, $P<0.05$ ), while the luciferase activity with the plasmid containing BREs 1-3 was essentially identical to pGL3-P indicating that only the region containing elements BRE 5 and 6 functions as a repressor. Practically identical results with plasmids pGL3-BRE1-3, pGL3-BRE5-6 and the control pGL3-P were obtained in the colon cancer cell lines HT-29 and Co-115/3 (Fig. 5C), although due to low transfection efficiency, variability was larger than in the Caco-2 cells. Thus, in all colon cancer cells tested, the region containing BREs 5 and 6 repressed the butyrate-induced luciferase activity.

To further narrow down the putative BREs, plasmids containing mutations in either the BRE5 (pGL3-BRE5mut-6) or BRE6 (pGL3BRE5-6mut) were constructed and results are presented in Figure 5D. In the luciferase assays, the activity of the control plasmid pGL3-P was set at 100\%; $100 \pm 0.9$ (Mean \pm SEM; $n=38$ samples). For pGL3-BRE5-6 the values were $60.1 \pm 2.2(n=33)$ Mutations in BRE5 restored the luciferase activity approximately half way to $79.1 \pm 2.5 ; n=31$ ), that is, approximately $50 \%$ of the repression mediated by pGL3-BRE5-6 was lost. Also the luciferase activity of a plasmid with mutations in BRE6 had a similar effect, the butyrate-induced repression was diminished to $82.1 \pm 6.1 ; \mathrm{n}=9$. When combining the effects of mutations in both BRE 5 and 6 , the 


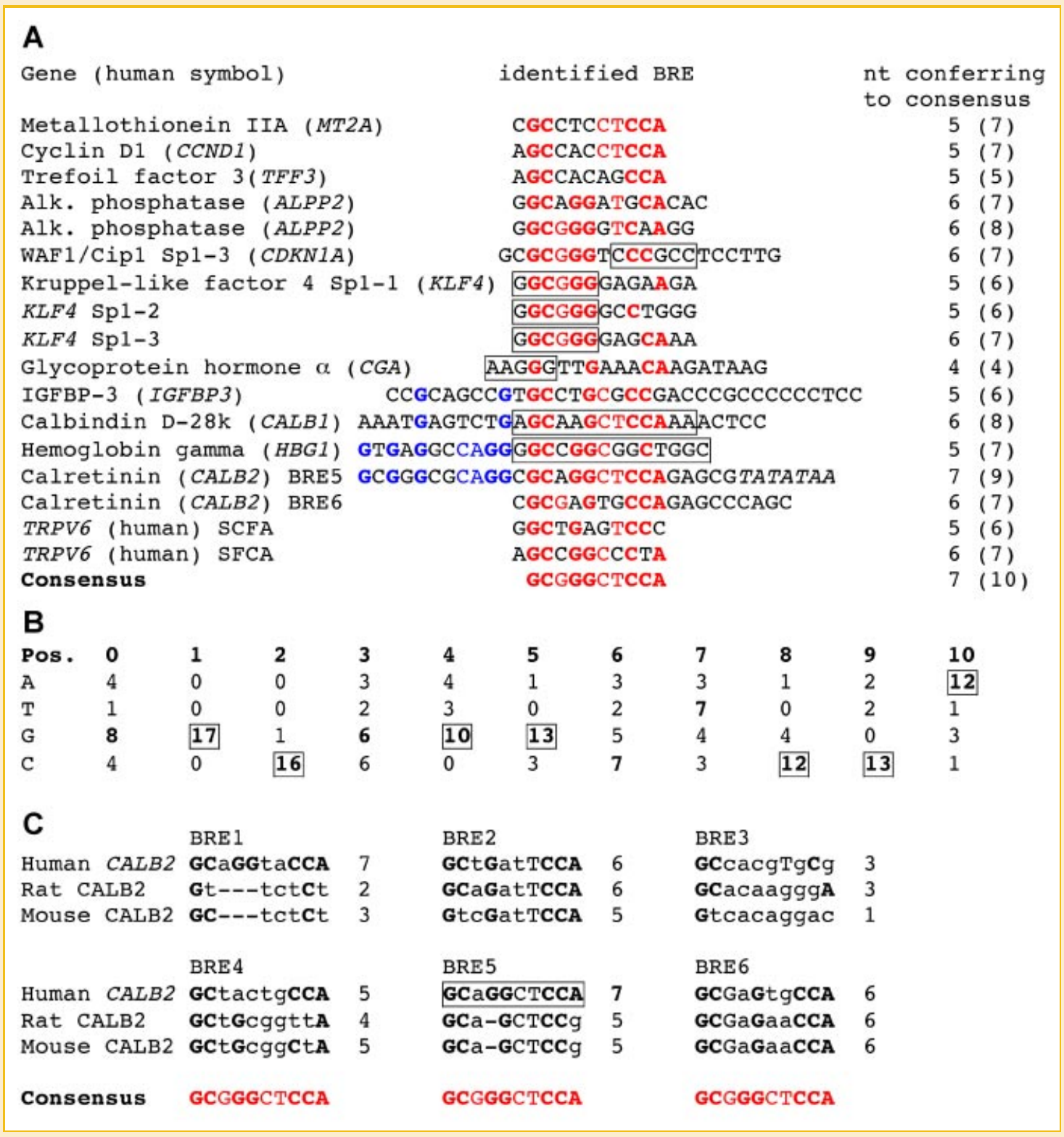

Fig. 4. A: Putative butyrate-responsive elements (BRE) in the promoter regions of genes regulated by butyrate (for abbreviations, see below). The consensus sequence embracing 10 nucleotides is marked in red as well as nucleotides in the promoter region of the various genes conferring to the consensus sequence. Nucleotides found more than 10 times in the total of 17 sequences are additionally marked in bold. The sequences of putative BREs reported in previous studies are boxed and often overlap with Sp1 sites (for details, see results). The numbers of nucleotides conferring to bold nucleotides within the consensus BRE are shown in the right lane, numbers in brackets also include the less-well conserved nucleotides of the consensus. In the gamma globin gene, additional $G$ (blue) preceding the consensus sequence was identified as recognition sites for proteins binding to the consensus (for details, see Results Section). B: At each of the 10 positions of the consensus, the distribution of nucleotides of the 17 analyzed sequences is shown; nucleotides most often present in that position are marked in bold and nucleotides occurring more than 10 times are boxed. C: Comparison of the six putative BREs in the promoter region of the CALB2 gene in different species. Highly consensus nucleotides are marked in bold, the ones conferring to the consensus sequence are in capitals and the nucleotides not conferring to the consensus are in miniscule. The number of nucleotides conferring to the consensus sequence of each BRE is listed. Abbreviations of genes and gene symbols: MT2A, Metallothionein IIA; CCND1, cyclin D1; TFF3, intestinal trefoil factor; ALPPL2, alkaline phosphatase, placental-like 2; CDKN1A, cyclin-dependent kinase inhibitor 1A (p21, Waf1) [Nakano et al., 1997]; KLF4, Kruppel-like factor 4 (a zinc finger-containing transcription factor with diverse regulatory functions in cell growth, proliferation, differentiation, and embryogenesis [Chen et al., 2004]; CGA, glycoprotein hormone, alpha polypeptide (GPHA1, GPHa,); IGFBP3, insulinlike growth factor binding protein 3 [Tsubaki et al., 2002]; HBG1, hemoglobin, gamma A; TRPV6, transient receptor potential vanilloid type 6 [Fukushima et al., 2009]; SCFA, Short-chain fatty acid. 

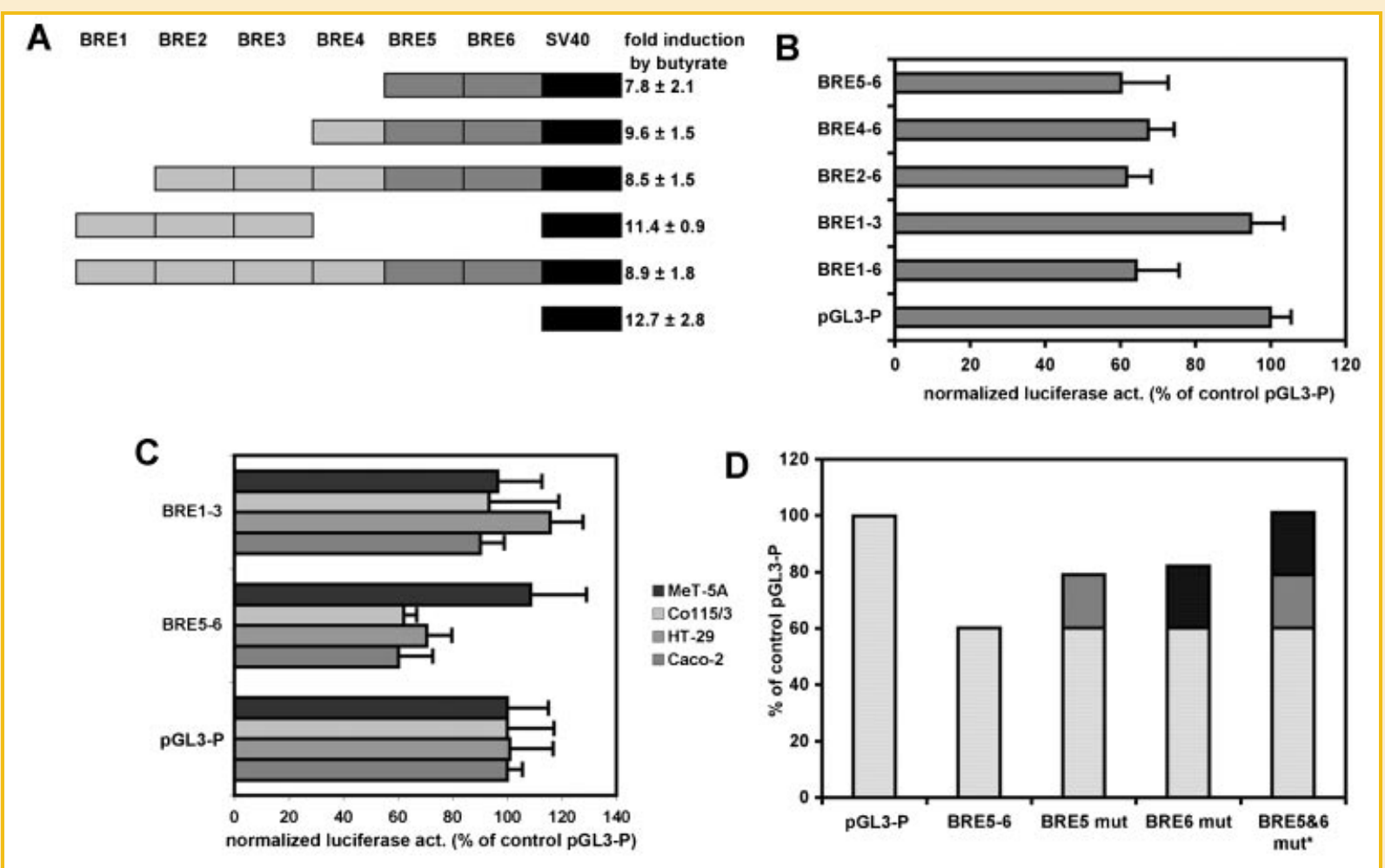

Fig. 5. Luciferase reporter assay with various parts of the CALB2 promoter region. A: The plasmid pGL3-P containing a SV40 minimal promoter (black box) was used as a control. Various parts of the CALB2 promoter region containing putative BREs were cloned upstream of the SV40 minimal promoter. The fold induction of luciferase activity due to butyrate treatment of Caco-2 cells is reported. B: For the normalization, the value of the control plasmid pGL3-P was set to 100\%. Using the four plasmids containing BREs 5 and 6 (dark gray box), the luciferase activity was decreased by approximately $40 \%$, while the plasmid containing BRE1-3 showed a similar activity as the control plasmid. A twoway ANOVA revealed the six groups to be different $(P<0.0001)$. For comparing the effect of individual plasmids with the control (pGL3-P), Dunnett's test was used, a more conservative test than pairwise $t$-tests, because it takes into account multiple comparisons. The results show that all plasmids containing BRE5 and 6 are significantly different from the control plasmid (for all plasmids $P<0.05$ ), while this is not the case for the plasmid containing BRE1-3. The results indicate that the CALB2 promoter region containing BRE5 and 6 acts as a repressor in Caco-2 cells. C: The CALB2 promoter region containing BRE5 and 6 acts as a repressor in all colon cancer cells tested (Caco-2, HT-29 and $\mathrm{Co115/3),} \mathrm{but} \mathrm{not} \mathrm{in} \mathrm{the} \mathrm{mesothelial} \mathrm{cell} \mathrm{line} \mathrm{MeT-5A.} \mathrm{The} \mathrm{repressor} \mathrm{activity} \mathrm{is} \mathrm{not} \mathrm{enclosed} \mathrm{in} \mathrm{the} \mathrm{region} \mathrm{containing} \mathrm{BRE1-3.} \mathrm{The} \mathrm{larger} \mathrm{standard} \mathrm{deviations} \mathrm{observed} \mathrm{in} \mathrm{cell}$ lines HT-29, Co1 15/3, and MeT-5A are due to the rather poor transfection efficiencies compared to Caco-2 cells. D: Introducing mutations in BRE5 (light gray) and BRE6 (dark gray; for details, see Fig. 1C) increased the luciferase activity by approximately $20 \%$ for each BRE. Adding the effects brought about by the mutations in either BRE5 or BRE6 (BRE5 and 6 mut $^{*}$ ) resulted in a luciferase activity as observed with the control plasmid pGL3-P.

luciferase activity reached again close to $100 \%$. Thus, the two elements BRE5 and BRE6 contributed to the repression and each of the elements had a similar contribution to the effect.

\section{BUTYRATE AFFECTS SURVIVAL OF MESOTHELIAL AND MESOTHELIOMA CELLS, BUT BRES 5 AND 6 DO NOT ACT AS BUTYRATE-DEPENDANT REPRESSORS}

Aberrant CR expression occurs in certain colon cancer cell lines [Gotzos et al., 1996a] and in a majority of GIII colon tumors [Gotzos et al., 1999], but is also observed in almost all mesotheliomas of the epitheloid and the mixed type [Doglioni et al., 1996; Gotzos et al., 1996b]. Thus, we tested whether butyrate also affects proliferation of mesothelial and mesothelioma cells as well as CR expression levels in these cells. For this, we used the mesothelial cell line MeT-5A and the mesothelioma cell line ZL34 [Saydan et al., 2001]. The MTT signal in butyrate-treated MeT-5A cells transiently decreased in a concentration-dependent manner and similar results were obtained for ZL34 cells (not shown). However, unlike in colon cancer cells, where butyrate treatment leads to a prolonged blockage of cell proliferation and morphological changes typical for differentiation (e.g., flattening of the cells, appearance of brush border [Cargnello et al., 1996]), the decreased MTT signal in the cells of mesothelial origin was principally caused by a rather massive cell death (necrosis and apoptosis) evidenced by detached and floating cells (not shown). Many remaining cells were characterized by a retraction, that is, reduced cell-cell contacts, condensed and pycnotic nuclei, membrane blebbing, all signs of apoptotic cell death (Fig. 6B). Cell death was quantified and compared in cells of mesothelial (MeT-5A) and of epithelial (HT-29) origin subjected to maximally $7.5 \mathrm{mM}$ butyrate for 36 or $24 \mathrm{~h}$ (Fig. 6D,E, respectively). Both, the amount of necrotic (Fig. 6D) and apoptotic (Fig. 6E) cells increased in a dosedependent manner in MeT-5A cells, while cell death was only minimally increased in HT-29 cells. As reported before in the closely related WiDr cells [Schwaller and Herrmann, 1997], butyrate treatment results in HT-29 cells forming either compact cell clusters or individual large cells characterized by a flattened morphology. Interestingly, a fraction of MeT-5A cells survived the treatment and continued to grow even in the presence of up to $10 \mathrm{mM}$ butyrate. The 


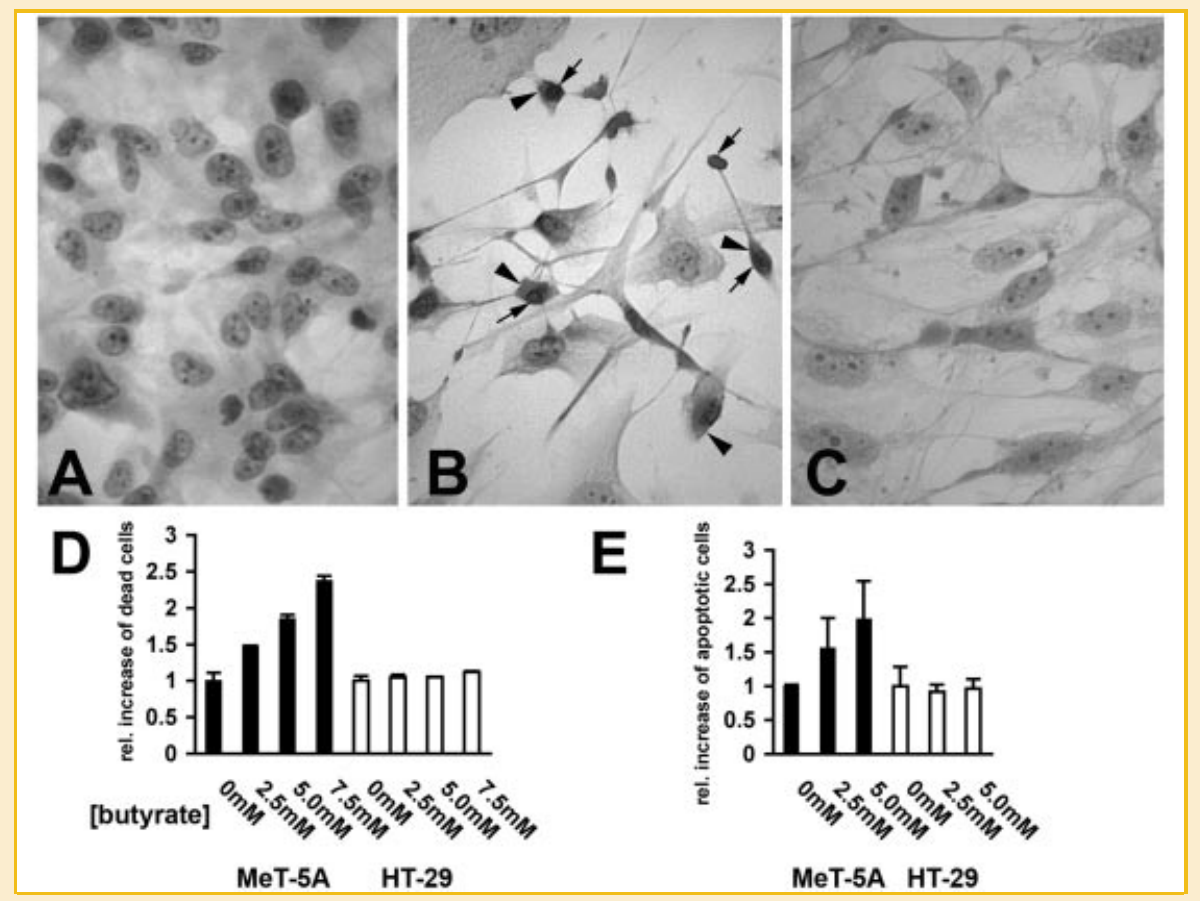

Fig. 6. HE staining of butyrate-treated MeT-5A cells and butyrate-induced cell death in MeT-5A and HT-29 cells. Control MeT-5A cells were grown in the absence of butyrate (A) or treated with $10 \mathrm{mM}$ butyrate for $48 \mathrm{~h}$ (B) or 6 days (C). A: Untreated MeT-5A cells formed a regular layer of flattened polygonal cells. Nuclei contain various numbers of small round-shaped heterochromatin structures and the cytoplasm is faintly stained by eosin. B: Cells that remained attached to the cover slip after treatment with butyrate had lost most of their cell-cell contacts. Many cells were characterized by irregular shaped, condensed pycnotic nuclei (arrows) and the cytoplasm surrounding the condensed nuclei showed strong eosinophilia (arrowheads). C: The small fraction of MeT-5A cells that initially survived the butyrate treatment continued to proliferate and cells were able to form a near-confluent layer. In comparison to untreated cells, more filamentous structures in the cytoplasm were visible and cell nuclei tended to be slightly larger. Thus, even in the continuous presence of $10 \mathrm{mM}$ butyrate, MeT-5A cells continue to proliferate indicating that butyrate does not have a principal function in the induction of differentiation in cells of mesothelial origin. Determination of necrotic (D) and apoptotic (E) cell death induced by butyrate in MeT-5A and HT-29 cells, cells of mesothelial and epithelial origin, respectively. Cells were treated with various butyrate concentrations (0-7.5 mM) and cell death was assayed $24 \mathrm{~h}$ (E; apoptosis) or $36 \mathrm{~h}$ (D; necrosis) later. Cell death was normalized to untreated control cells (control $=1$ ). Values are the average of two independent experiments $(\mathrm{mean} \pm \mathrm{SD})$.

morphology of surviving cells (Fig. 6C) again resembled the one of untreated cells (Fig. 6A), although some differences in cell shape persisted. Thus, the effect of butyrate on mesothelial cells is rather a cytotoxic (necrotic and apoptotic; Fig. 6D,E) than a differentiationinducing one. Concomitantly, CR expression levels in MeT-5A cells were not affected by butyrate at a concentration of 1 or $2 \mathrm{mM}$, a dose not leading to massive cell death; this is seen by the essentially unchanged Western blot signals in cells treated with 1 or $2 \mathrm{mM}$ butyrate (Fig. 3B). At $5 \mathrm{mM}$ butyrate, the minute number of MeT-5A cells surviving this treatment after 5-6 days did not allow to obtain enough protein for Western blot analysis. On average CR expression levels were marginally increased $(<20 \%)$ after treatment of cells with $1 \mathrm{mM} \mathrm{NaBt}$ and slightly decreased $(<20 \%)$ in cells treated with $2 \mathrm{mM}$ ( $P>0.1$ vs. control for both $\mathrm{NaBt}$ concentrations). The luciferase activity in NaBt-treated MeT-5A cells was only minimally increased (1.5- to 1.8-fold compared to $>10$-fold in colon cancer cells) and when expressed in relative terms, no differences were observed when the constructs with BRE1-3 (1.7 \pm 0.5$)$ and BRE5-6 $(1.8 \pm 0.1)$ were compared to the control plasmid pGL3-P without the $C A L B 2$ promoter region $(1.8 \pm 0.2)$. The fold induction was even lower in the mesothelioma cell line ZL 34 cells: $1.3 \pm 0.3$ for the control plasmid pGL3-P, $0.9 \pm 0.3$ for the plasmid containing elements BRE5-6 $(P>0.1)$. Thus, butyrate has a rather cytotoxic effect on cells of mesothelial origin (MeT-5A and ZL34) and the BRE elements 5 and 6 in the CALB2 promoter do not act as functional repressors of $\mathrm{CR}$ expression in these cells.

\section{DISCUSSION}

Butyrate present at millimolar concentrations in the lumen of the digestive tract including the colon is taken up by the epithelial cells and is used as a primary source for energy metabolism, but additionally acts as an agent inducing differentiation of these cells. Thus, a diet rich in dietary fibers leading to elevated butyrate levels decreases the incidence of colon tumors evidenced in epidemiological studies [reviewed in Reddy, 2000]. Butyrate acts as an established histone deacetylase inhibitor by favoring an active chromatin configuration. A number of genes is positively or negatively regulated by butyrate and in the last years, several studies aimed to elucidate the genes and moreover gene networks, in both normal colonocytes and colon cancer cells that are affected by butyrate [Mariadason et al., 2000; Iacomino et al., 2001; Tabuchi et al., 2002, 2006]. A common finding in most studies is the blockage of genes involved in cell cycle regulation (e.g., cyclin D1) and the transient induction of genes such as p21 (Cip/Waf1), an inhibitor of 
cyclin-dependent protein-kinases. Among the many genes whose expression is modulated by butyrate, butyrate-responsive elements (BREs) were identified in the promoter region of several ones, mostly by in vitro promoter analysis. The detailed analysis of available BRE sequences (Fig. 4) allowed us to deduce a consensus sequence that was rather well conserved in most of the reported BREs and consists of the sequence GCnGGnnCCA. In genes regulated by butyrate, this conserved element is often closely spaced to the TATA box region; in the genes CDKN1A, KLF4, HBG, and CALB2, the BREs are only 4-32 nucleotides upstream of the TATA box and in the CALB1 and CGA genes, the distance is less than 150 nucleotides. This is unlike for other elements such as cAMP-responsive (CRE), vitamin D-responsive (VDRE) or retinoic acid-responsive (RAR and RXR) elements that are often several kilobases away from the TATA box or the transcription start site.

CR normally expressed in specific neurons of the central and peripheral nerve system as well as in few other cell types, is aberrantly expressed in several type of tumors, in particular in poorly differentiated colon tumors [Gotzos et al., 1999] and in certain mesotheliomas [Doglioni et al., 1996; Gotzos et al., 1996b]. Also in vitro in colon cancer cell lines, diverse expression levels of CR were observed: low expression in cell lines derived from well-tomoderately differentiated tumors (e.g., Caco-2) and high expression in cell lines derived from poorly differentiated ones (HT-29, WiDr, Co-115/3) [Gotzos et al., 1996a]. This additionally correlated well with the growth-inhibiting sensitivity to butyrate as evidenced for Caco-2, HT-29 and analyzed in more detail for Co-115/3 cells. The latter cells did not only show the highest resistance to the growthinhibiting effect of butyrate, but also had the highest CR expression levels. Based on the previous finding that addition of butyrate to cultured colon cancer cells not only blocks cell growth, but at the same time down-regulates the expression of CR [Schwaller and Herrmann, 1997; Marilley et al., 2001], we hypothetized that the promoter region of the CALB2 gene might contain BREs acting as repressors. Analysis of the promoter region of human, rat and mouse CALB2 revealed six putative BREs contained in a region of approximately $1.5 \mathrm{~kb}$ upstream of the first exon. Globally, the six BREs (with the exception of BRE2) were highly conserved in the three species. The functionality of the BREs was analyzed in the three colon cancer cell lines Co-115/3, HT-29, and Caco-2. A deletion analysis of the $1.5 \mathrm{~kb}$ region revealed to enclose one or several elements acting as repressors of butyrate-induced luciferase expression in the region surrounding the TATA box and containing the BREs 5 and 6 . In all the three cell lines essentially identical results were obtained, that is, a $40 \%$ reduction in luciferase activity after $48 \mathrm{~h}$ compared to the control plasmid without the CALB2 region. Mutations in either BRE 5 or BRE 6 reduced the repressor effect by approximately 50\% each indicating that both elements contribute to the butyrate-induced repression of $\mathrm{CR}$ expression. Since aberrant expression of $\mathrm{CR}$ is also the hallmark of mesotheliomas, in particular of the epithelial type, we used either the SV40-immortalized cell line MeT-5A or the mesothelioma cell line ZL34 that both express CR [Henzi et al., 2009] and [Saydan et al., 2001], respectively. Unlike in colon cancer cells, where butyrate mainly affects proliferation, doses of $>1 \mathrm{mM}$ led to massive death of cells of mesothelial origin starting from the third day of butyrate treatment. Before this time point, proliferation was similar or even slightly increased in butyrate-treated cells of mesothelial origin. While the addition of butyrate to colon cancer cells induces morphological changes from a pavement-like appearance of untreated cells to a more flattened morphology with a larger nucleus and clear cytoplasm, butyrate-treated MeT-5A cells showed cell swelling, rounding and detachment from the culture dishes typical for cell death and also signs of apoptosis were detected (e.g., pycnotic fragmented nuclei) as described before in the mesothelioma cell lines REN and I-45 [Cao et al., 2001]. In MeT-5A cells treated with "tolerable" doses of butyrate (1 and $2 \mathrm{mM}$ ), expression levels of CR were essentially unchanged. In the reporter assay, the region containing BREs 5 and 6 did not repress the butyrate-induced luciferase activity. Thus, in cells of mesothelial origin, the BREs are non-functional. This came not as a real surprise, since under physiological conditions, mesothelial cells are probably exposed to very low butyrate concentrations. In the feces butyrate may reach levels of $70 \mu \mathrm{mol} / \mathrm{g}$ wet weight translating to values of up to $10 \mathrm{mM}$. A majority (85-90\%) of butyrate is taken up by colonocytes, thereby providing a substantial energy supply for these cells [Roediger, 1982]. The remaining butyrate ends up in the portal vein and transiently increases the circulating level of butyrate [Bach Knudsen et al., 2003]. Before reaching mesothelial cells (e.g., in the peritoneum) butyrate needs to traverse the endothelium of blood vessels and then the connective tissue. On the one hand, the colonic mucosa is constantly exposed to millimolar concentrations of butyrate, which plays an important role in the homeostasis of the colonic mucosa by, for example, suppressing cell proliferation, inducing differentiation and also playing a role in apoptosis. As a consequence butyrate functions as a physiological signaling molecule in colonocytes, affecting various cellular processes, also at the level of transcription. On the other hand, such a physiological signaling role in cells of mesothelial origin appears rather unlikely, however it cannot be entirely excluded. Nonetheless, butyrate was previously shown to increase cell death in mesothelioma cells by decreasing the levels of the anti-apoptotic protein BCL-XL [Cao et al., 2001].

What are the implications of the butyrate-induced downregulation of $\mathrm{CR}$ expression in colon cancer cells? The standard adjuvant chemotherapy for colon cancer consists of 5-fluorouracil (5-FU) treatment, nowadays often in combination with oxaliplatin [Allen et al., 2006]. The success rate of 5-FU treatment alone is rather low (10-20\%), mainly as the result of 5-FU resistance of a small fraction of cancer cells [Lesuffleur et al., 1991] leading to the recurrence of the tumor [Longley et al., 2006]. An analysis of 5-FUsensitive and 5-FU-resitant cells revealed that besides the mRNA of prostate-derived factor ( $P D F$, a member of the TGF-beta family) and spermidine/spermine N1-acetyl transferase (SSAT), the one that was constitutively upregulated was the CALB2 mRNA [Boyer et al., 2006]. In addition, acute treatment of HT-29 cells with an $\mathrm{IC}_{50}$ dose of 5-FU or oxaliplatin resulted in a two- to fourfold larger CALB2 signal. In this study this was interpreted as an upregulation of CALB2 mRNA, but in view of the fact that many cells die during the 5-FU treatment, the increase in CALB2 mRNA could also be considered as an accumulation (selection) of resistant cells with higher CR expression. Even "pure” cell lines are more heterogeneous 
than previously thought; all four tested clones derived from HT-29 cells differentiated after butyrate treatment, but showed differences in their response with respect to some of the markers [Stokrova et al., 2006]. Along the same line, we have previously observed that CR expression levels in HT-29 or the closely related WiDr cells are not homogenous and the strongest immunoreactivity is seen in proliferative cells at the border of cell clusters or in dividing cells [Gotzos et al., 1992; Cargnello et al., 1996]. In the study by Boyer et al. [2006] knockdown of CR expression with siRNA did not affect basal levels of apoptosis evidenced by unchanged PARP cleavage, but significantly reduced programmed cell death when combined with 5-FU or oxaliplatin. Since the induction of a more differentiated phenotype in WiDr or HT-29 cells by either butyrate [Marilley et al., 2001] or glucose starvation [Cargnello et al., 1996], respectively, goes together with a decrease in CR expression, we hypothesize that 5-FU and oxaliplatin are more efficient cytotoxic agents in proliferating cells in vitro than in ones, where the cell cycle is already entirely blocked. Knockdown of CR expression by antisense oligo nucleotides in WiDr cells blocks the cycle mainly at G1/S [Gander et al., 1996]. Thus, this apparent protection against 5-FU cytotoxicity might be due to the cell cycle silencing effect induced by CR downregulation. In vivo the situation appears to be different. 5-FU-resistant colon tumors in rats were highly responsive to a butyrate/IL-2 bi-therapy [Cordel et al., 1997]. The median survival time of rats with 5-FU resistant tumors was considerably enhanced by concomitant treatment with butyrate/IL-2. Four out of five rats were still alive 250 days after treatment and were considered cured, while median survival time for rats treated only with 5-FU was 85 days. Also growth of human colorectal cancers grafted into nude mice was stronger inhibited with the combination of 5-FU and the stable butyrate derivative (3n-But) than with 5-FU alone irrespective of their p53 and microsatellite instability status [Bras-Goncalves et al., 2001]. The main effect was a blockage of cell proliferation without affecting cell differentiation and significantly enhanced apoptosis, while treatment with 5-FU or 3n-But alone stopped the cycle in S and in G1 phase, respectively. We postulate that the gradual down-regulation of CR by butyrate would slow down proliferation, and possibly shift the cells towards a more differentiated phenotype that renders the surviving 5-FU-resistant tumor cells again sensitive to the action of 5-FU. Thus, the better survival of rats subjected to the 5-FU/butyrate combination may lie in the suppression of CR expression and/or the modulation of expression of other butyrate-sensitive genes through the action of butyrate. Whether this therapy might be also successfully applied in humans remains to be shown, but the fact the CALB2 promoter is directly responsive to butyrate makes the $C A L B 2$ gene a putative target for a novel cancer therapy.

An unexpected link between colon cancer and $\mathrm{Ca}^{2+}$ signaling was provided by Bush et al. [2007]. One of the genes induced in early stage colon cancer by butyrate is PPAR $\gamma$ known to inhibit tumor cell growth through induction of G1-phase arrest, leading to irreversible withdrawal from the cell cycle. A microarray study of cells treated with the PPAR $\gamma$ agonist thiazolidinedione revealed a link between PPAR $\gamma$ and Down syndrome critical region 1 (DSCR1), an endogenous calcineurin inhibitor. DSCR1 blocks dephosphorylation of NFATc, thereby preventing the translocation of the activated form to the nucleus. Downregulation of DSCR1 suppresses the inhibition of proliferation exerted by PPAR $\gamma$. A link between PPAR $\gamma$, mitochondria and $\mathrm{Ca}^{2+}$ signaling has been shown before, but this additional link via DSCR1 and calcineurin indicates that altered $\mathrm{Ca}^{2+}$ regulation may also have a distinct role in transformation of epithelial cells to colon cancer cells. In addition, PPAR-ligands, independently from their PPAR binding specificity, can induce a derangement of the mitochondrial respiratory chain resulting from a strong inhibition of oxidative phosphorylation complexes including complexes II + III, IV, V, and VI [Nadanaciva et al., 2007]. These complexes are necessary to maintain the electrochemical gradient across the mitochondria membrane that is used to drive the mitochondrial $\mathrm{Ca}^{2+}$ uptake. Thus, PPAR agonists may have an additional effect on $\mathrm{Ca}^{2+}$ signaling in cancer cells via blocking mitochondrial $\mathrm{Ca}^{2+}$ uptake. Furthermore, butyrate upregulates plasma membrane calcium ATPase (PMCA) isoform 4 in HT-29 cells, but not affecting PMCA1 [Aung et al., 2007], in further support that specific alterations in $\mathrm{Ca}^{2+}$ signaling may play a role in colon cancer tumorigenesis. Thus, the $\mathrm{Ca}^{2+}$-buffer $\mathrm{CR}$ also reported to possibly have additional " $\mathrm{Ca}^{2+}$ sensor" functions [BillingMarczak and Kuznicki, 1999; Faas et al., 2007] may be implicated directly or indirectly in affecting colon cancer cell $\mathrm{Ca}^{2+}$ signaling and thereby exerting a protective effect against drug-induced cytotoxicity.

\section{ACKNOWLEDGMENTS}

The authors wish to thank Dr. Tadeusz J. Kawecki, University of Lausanne, Switzerland for the help in the statistical analysis. The project was supported by the Swiss National Science Foundation (grants $3100-063448.00 / 1$ and $310000-113518 / 1$ to B.S.).

\section{REFERENCES}

Allen WL, Coyle VM, Johnston PG. 2006. Predicting the outcome of chemotherapy for colorectal cancer. Curr Opin Pharmacol 6:332-336.

Aung CS, Kruger WA, Poronnik P, Roberts-Thomson SJ, Monteith GR. 2007. Plasma membrane Ca2+-ATPase expression during colon cancer cell line differentiation. Biochem Biophys Res Commun 355:932-936.

Bach Knudsen KE, Serena A, Canibe N, Juntunen KS. 2003. New insight into butyrate metabolism. Proc Nutr Soc 62:81-86.

Baimbridge KG, Celio MR, Rogers JH. 1992. Calcium-binding proteins in the nervous system. Trends Neurosci 15:303-308.

Bearzatto B, Servais L, Roussel C, Gall D, Baba-Aissa F, Schurmans S, de Kerchove d'Exaerde A, Cheron G, Schiffmann SN. 2006. Targeted calretinin expression in granule cells of calretinin-null mice restores normal cerebellar functions. FASEB J 20:380-382.

Billing-Marczak K, Kuznicki J. 1999. Calretinin-sensor or buffer-function still unclear. Pol J Pharmacol 51:173-178.

Boyer J, Allen WL, McLean EG, Wilson PM, McCulla A, Moore S, Longley DB, Caldas C, Johnston PG. 2006. Pharmacogenomic identification of novel determinants of response to chemotherapy in colon cancer. Cancer Res 66:2765-2777.

Bras-Goncalves RA, Pocard M, Formento JL, Poirson-Bichat F, De Pinieux G, Pandrea I, Arvelo F, Ronco G, Villa P, Coquelle A, Milano G, Lesuffleur T, Dutrillaux B, Poupon MF. 2001. Synergistic efficacy of 3n-butyrate and 5-fluorouracil in human colorectal cancer xenografts via modulation of DNA synthesis. Gastroenterology 120:874-888. 
Bush CR, Havens JM, Necela BM, Su W, Chen L, Yanagisawa M, Anastasiadis PZ, Guerra R, Luxon BA, Thompson EA. 2007. Functional genomic analysis reveals crosstalk between peroxisome proliferator-activated receptor gamma (PPARgamma) and calcium signaling in human colorectal cancer cells. J Biol Chem 282:23387-23401.

.Cao XX, Mohuiddin I, Ece F, McConkey DJ, Smythe WR. 2001. Histone deacetylase inhibitor downregulation of bcl-xl gene expression leads to apoptotic cell death in mesothelioma. Am J Respir Cell Mol Biol 25:562568.

Cargnello R, Celio MR, Schwaller B, Gotzos V. 1996. Change of calretinin expression in the human colon adenocarcinoma cell line HT29 after differentiation. Biochim Biophys Acta 1313:201-208.

Carrel S, Sordat B, Merenda C. 1976. Establishment of a cell line (Co115) from a human colon carcinoma transplanted into nude mice. Cancer Res 36:39783984.

Chen ZY, Rex S, Tseng CC. 2004. Kruppel-like factor 4 is transactivated by butyrate in colon cancer cells. J Nutr 134:792-798.

Cordel S, Heymann MF, Boisteau 0, Oliver L, Le Pendu J, Gregoire M, Meflah K. 1997. 5-Fluorouracil-resistant colonic tumors are highly responsive to sodium butyrate/interleukin-2 biotherapy in rats. Int J Cancer 73:924928.

Daly K, Cuff MA, Fung F, Shirazi-Beechey SP. 2005. The importance of colonic butyrate transport to the regulation of genes associated with colonic tissue homoeostasis. Biochem Soc Trans 33:733-735.

Doglioni C, Tos APD, Laurino L, Iuzzolino P, Chiarelli C, Celio MR, Viale G. 1996. Calretinin: A novel immunocytochemical marker for mesothelioma. Am J Surgical Pathol 20:1037-1046.

Faas GC, Schwaller B, Vergara JL, Mody I. 2007. Resolving the fast kinetics of cooperative binding: Ca2+ buffering by calretinin. PLoS Biol 5:e311. 10.1371/journal.pbio.0050311.

Fukushima A, Aizaki Y, Sakuma K. 2009. Short-chain fatty acids induce intestinal transient receptor potential vanilloid type 6 expression in rats and Caco-2 cells. J Nutr 139:20-25.

Gander JC, Gotzos V, Fellay B, Schwaller B. 1996. Inhibition of the proliferative cycle and apoptotic events in WiDr cells after down-regulation of the calcium-binding protein calretinin using antisense oligodeoxynucleotides. Exp Cell Res 225:399-410.

Gill RK, Christakos S. 1993. Identification of sequence elements in mouse calbindin-D28k gene that confer 1,25-dihydroxyvitamin D3- and butyrateinducible responses. Proc Natl Acad Sci USA 90:2984-2988.

Gotzos V, Schwaller B, Hetzel N, Bustos-Castillo M, Celio MR. 1992. Expression of the calcium binding protein calretinin in WiDr cells and its correlation to their cell cycle. Exp Cell Res 202:292-302.

Gotzos V, Schwaller B, Gander JC, Bustos-Castillo M, Celio MR. 1996a. Heterogeneity of expression of the calcium-binding protein calretinin in human colonic cancer cell lines. Anticancer Res 16:3491-3498.

Gotzos V, Vogt P, Celio MR. 1996b. The calcium binding protein calretinin is a selective marker for malignant pleural mesotheliomas of the epithelial type. Pathol Res Pract 192:137-147.

Gotzos V, Wintergerst ES, Musy JP, Spichtin HP, Genton CY. 1999. Selective distribution of calretinin in adenocarcinomas of the human colon and adjacent tissues. Am J Surg Pathol 23:701-711.

Haas MJ, Cosgrove DE, Xiong W, Cox GS. 1999. Sodium butyrate-mediated induction of the glycoprotein hormone alpha-subunit gene: Requirement for continued protein synthesis, identification of a butyrate-responsive element, and inhibition of promoter activation by 2-deoxyglucose. J Cell Biochem 74:242-263.

Henzi T, Blum WV, Pfefferli M, Kawecki TJ, Salicio V, Schwaller B. 2009. SV40-induced expression of calretinin protects mesothelial cells from asbestos cytotoxicity and may be a key factor contributing to mesothelioma pathogenesis. Am J Pathol 174:2324-2336.
Iacomino G, Tecce MF, Grimaldi C, Tosto M, Russo GL. 2001. Transcriptional response of a human colon adenocarcinoma cell line to sodium butyrate. Biochem Biophys Res Commun 285:1280-1289.

Lallemand F, Courilleau D, Sabbah M, Redeuilh G, Mester J. 1996. Direct inhibition of the expression of cyclin D1 gene by sodium butyrate. Biochem Biophys Res Commun 229:163-169.

Lamprecht SA, Lipkin M. 2003. Chemoprevention of colon cancer by calcium, vitamin D and folate: Molecular mechanisms. Nat Rev Cancer 3: 601-614.

Lesuffleur T, Kornowski A, Augeron C, Dussaulx E, Barbat A, Laboisse C, Zweibaum A. 1991. Increased growth adaptability to 5-fluorouracil and methotrexate of HT-29 sub-populations selected for their commitment to differentiation. Int J Cancer 49:731-737.

Longley DB, Allen WL, Johnston PG. 2006. Drug resistance, predictive markers and pharmacogenomics in colorectal cancer. Biochim Biophys Acta 1766:184-196.

Mariadason JM, Corner GA, Augenlicht LH. 2000. Genetic reprogramming in pathways of colonic cell maturation induced by short chain fatty acids: Comparison with trichostatin A, sulindac, and curcumin and implications for chemoprevention of colon cancer. Cancer Res 60:4561-4572.

Marilley D, Vonlanthen S, Gioria A, Schwaller B. 2001. Calretinin and calretinin-22k increase resistance towards sodium butyrate-induced differentiation in CaCo-2 colon adenocarcinoma cells. Exp Cell Res 268:93-103.

Nadanaciva S, Dykens JA, Bernal A, Capaldi RA, Will Y. 2007. Mitochondrial impairment by PPAR agonists and statins identified via immunocaptured OXPHOS complex activities and respiration. Toxicol Appl Pharmacol 223: 277-287.

Nakano K, Mizuno T, Sowa Y, Orita T, Yoshino T, Okuyama Y, Fujita T, Ohtani-Fujita N, Matsukawa Y, Tokino T, Yamagishi H, Oka T, Nomura H, Sakai T. 1997. Butyrate activates the WAF1/Cip1 gene promoter through Sp1 sites in a p53-negative human colon cancer cell line. J Biol Chem 272:2219922206.

Racay P, Gregory P, Schwaller B. 2006. Parvalbumin deficiency in fast-twitch muscles leads to increased 'slow-twitch type' mitochondria, but does not affect the expression of fiber specific proteins. FEBS J 273:96-108.

Rao J, Otto WR. 1992. Fluorimetric DNA assay for cell growth estimation. Anal Biochem 207:186-192.

Reddy BS. 2000. The Fourth DeWitt S. Goodman lecture. Novel approaches to the prevention of colon cancer by nutritional manipulation and chemoprevention. Cancer Epidemiol Biomarkers Prev 9:239-247.

Roediger WE. 1982. Utilization of nutrients by isolated epithelial cells of the rat colon. Gastroenterology 83:424-429.

Saydan N, Salicio V, Cappelli-Gotzos B, Gotzos V. 2001. Expression of calretinin in human mesothelioma cell lines and cell cycle analysis by flow cytometry. Anticancer Res 21:181-188.

Schmitter D, Lauber B, Fagg B, Stahel RA. 1992. Hematopoietic growth factors secreted by seven human pleural mesothelioma cell lines: Interleukin6 production as a common feature. Int J Cancer 51:296-301.

Schwab M, Reynders V, Ulrich S, Zahn N, Stein J, Schroder 0. 2006. PPARgamma is a key target of butyrate-induced caspase- 3 activation in the colorectal cancer cell line Caco-2. Apoptosis 11:1801-1811.

Schwaller B, Herrmann B. 1997. Regulated redistribution of calretinins in WiDr cells. Cell Death Differ 4:325-333.

Schwaller B, Buchwald P, Blumcke I, Celio MR, Hunziker W. 1993. Characterization of a polyclonal antiserum against the purified human recombinant calcium binding protein calretinin. Cell Calcium 14:639-648.

Schwaller B, Celio MR, Hunziker W. 1995. Alternative splicing of calretinin mRNA leads to different forms of calretinin. Eur J Biochem 230:424-430.

Siavoshian S, Blottiere HM, Le Foll E, Kaeffer B, Cherbut C, Galmiche JP. 1997. Comparison of the effect of different short chain fatty acids on the growth and differentiation of human colonic carcinoma cell lines in vitro. Cell Biol Int 21:281-287. 
Stokrova J, Sloncova E, Sovova V, Kucerova D, Zila V, Tureckova J, Vojtechova M, Korb J, Tuhackova Z. 2006. Characterization of four clones derived from human adenocarcinoma cell line, HT29, and analysis of their response to sodium butyrate. Int J Oncol 28:559-565.

Tabuchi Y, Arai Y, Kondo T, Takeguchi N, Asano S. 2002. Identification of genes responsive to sodium butyrate in colonic epithelial cells. Biochem Biophys Res Commun 293:1287-1294.

Tabuchi Y, Takasaki I, Doi T, Ishii Y, Sakai H, Kondo T. 2006. Genetic networks responsive to sodium butyrate in colonic epithelial cells. FEBS Lett 580:3035-3041.
Tran CP, Familari M, Parker LM, Whitehead RH, Giraud AS. 1998. Shortchain fatty acids inhibit intestinal trefoil factor gene expression in colon cancer cells. Am J Physiol 275:G85-G94.

Tsubaki J, Hwa V, Twigg SM, Rosenfeld RG. 2002. Differential activation of the IGF binding protein-3 promoter by butyrate in prostate cancer cells. Endocrinology 143:1778-1788.

Vonlanthen S, Kawecki TJ, Betticher DC, Pfefferli M, Schwaller B. 2007. A single nucleotide polymorphism (SNP) in intron 9 of the human calretinin gene is a risk factor and is linked to calretinin expression in colon tumors, but not in lung tumors. Anticancer Res 27:4279-4288. 